\title{
Loss of FHIT protein expression is related to high proliferation, low apoptosis and worse prognosis in non-small-cell lung cancer
}

\author{
Gemma Toledo, Jesús Javier Sola, Maria Dolores Lozano, Elena Soria and Javier Pardo \\ Department of Pathology, University of Navarra, Pamplona, Spain
}

\begin{abstract}
The fragile histidine triad (FHIT) gene, located at chromosome 3p14.2, is deleted in many solid tumors, including lung cancer. Its protein product is presumed to have tumor suppressor function. We investigated the incidence of loss of heterozygosity and loss of FHIT expression in a series of non-small-cell lung carcinomas and its correlation to apoptosis, proliferation index and prognosis. FHIT expression was determined by immunohistochemistry in formalin-fixed paraffin-embedded tissues from 54 squamous cell carcinomas (SCC) and 44 adenocarcinomas (AC) of the lung. DNA from frozen tumor and corresponding normal tissues were analyzed for allelic losses at two loci located internal (D3S1300, D3S1234) and three loci in flanking regions centromeric and telomeric (D3S1210, D3S1312, D3S1313) to the FHIT gene. Apoptosis was detected by terminal deoxynucleotidyltransferase-mediated dUTP nick end labeling (TUNEL). Proliferation index was determined with ki-67 and flow cytometric analysis. We correlated the results with tumor histology, prognosis and some immunohistochemical markers (p53, bcl-2, bax, c-myc, p21 waf1 , cyclin-D1). FHIT expression was related to tumor histology: 52 of $54(96.3 \%)$ SCC and 20 of $44(45.5 \%)$ AC were negative for FHIT $(P<0.0001)$. We found LOH at 3p14.2 in $67.8 \%$ of the 98 cases: $72.3 \%$ of SCC and $61.4 \%$ of AC. Loss of FHIT expression was associated with a higher proliferation index $(\mathrm{ki}-67, P=0.007$; flow cytometry, $P<0.004)$ and lower apoptotic index $(P=0.018)$. LOH at FHIT gene were associated to a high proliferation (flow cytometry, $P<0.001$ ) and lower apoptotic level $(P=0.043)$. The log-rank test demonstrated a significant inverse correlation $(P=0.039)$ between loss of FHIT expression and patient survival. FHIT plays an important role in the development of non-small-cell lung cancer, particularly in SCC. Loss of FHIT protein is correlated with a high proliferation and low apoptotic index in tumor cells, and is an independent prognostic indicator for the clinical outcome in patients with these tumors.
\end{abstract}

Modern Pathology (2004) 17, 440-448, advance online publication, 13 February 2004; doi:10.1038/modpathol.3800081

Keywords: non-small-cell lung carcinoma; FHIT; loss of heterozygosity; immunohistochemistry; apoptosis; Ki-67; flow cytometry

Lung cancer is the leading cause of death from malignancies in the world, according to the most recent studies in USA and the European Union. ${ }^{1,2}$ In spite of the advances in new strategies on therapy and diagnosis, the overall survival at 5 years is between 10 and $15 \%$, without any improvement during the last years. ${ }^{2}$

Squamous cell carcinoma (SCC) and adenocarcinoma (AC) are the most frequent histological types of non-small-cell lung cancer (NSCLC). The development of molecular studies in lung cancer cells often shows the accumulation of sequential genetic alterations, including alterations in oncogenes and

Correspondence: G Toledo, MD, PhD, Department of Pathology, Clínica Universitaria. Aptdo. 4209, Pamplona 31080, Spain.

E-mail: gtoledo@unav.es

Received 29 April 2003; revised 3 November 2003; accepted 11 November 2003; published online 13 February 2004 tumor suppressor genes, resulting in a multistep process of carcinogenesis.

The fragile histidine triad (FHIT) gene is a candidate tumor suppressor gene located at chromosome 3p14.2, spanning the FRA3B common fragile site. ${ }^{3}$ Frequent allelic losses and homozygous deletions, ${ }^{3-16}$ as well as the loss of heterozygosity (LOH) in microsatellites located at FHIT gene ${ }^{5,11,12,17-24}$ have been described at the FHIT locus in several human solid tumors arising from epithelial cells, including lung cancer.

The FHIT protein is homologous to Ap4A hydrolase from the yeast Schizosaccharomyces pombe and it also exhibits Ap3A activity in enzymatic assays. $^{3,4}$ FHIT protein is presumed to have tumor suppressor function independent of its hydrolase activity. ${ }^{3,25}$ However, the mechanisms through which FHIT mediates its suppressor function are not well established. Several investigators have 
shown that introduction of a wild-type FHIT gene suppresses tumorigenicity and the transfection of FHIT in FHIT - human cancer cells appear to induce apoptosis and inhibit cell growth. ${ }^{25-27}$ These results suggest that the suppressor activity of FHIT could be related with apoptosis and with the alteration of cell cycle regulator factors.

The availability of a reliable immunohisto chemical assay for FHIT expression has facilitated the assessment of protein expression in routinely fixed tissues. Studies comparing FHIT expression with the status of the FHIT gene have shown significant concordance in a variety of malignancies. The advantage of an immunohistochemical assay is that it can determine intratumoral FHIT levels irrespective of the mechanism of FHIT gene inactivation. Loss of FHIT expression has been correlated with a variety of clinicopathologic parameters such as disease stage, tumor progression and recurrence in several cancers, ${ }^{28-33}$ but the value of FHIT as a potential predictor marker of survival is not clear.

To determine the role of FHIT in the pathogenesis and progression of lung cancer, we investigated the incidence of LOH and loss of FHIT expression in a series of non-small-cell lung carcinomas and its relationship with apoptosis, tumor cell proliferation and clinical outcome.

\section{Materials and methods}

\section{Patients}

We selected 98 patients who underwent surgical resection from January 1994 to February 2000, for non-small-cell carcinoma at the Clínica Universitaria de Navarra (Pamplona, Spain). There were 85 men and 13 women, with a mean age of 62 (range 35-84) years. Histological type according to the WHO classification $^{34}$ corresponded to 54 SCCs and 44 ACs. Data of TNM and pathological stage, smoking habit, clinical history and evolution were recollected from each case (Table 1). All cases had neither received preoperative chemotherapy nor radiotherapy, had no distant metastases at diagnosis and the TNM classification was no T4.

Survival data were available for all patients with a mean follow-up of 3.61 years (9.6 months to 7.3 years).

\section{Immunohistochemistry}

New sections ( $4 \mu \mathrm{m}$ thickness) were obtained from paraffin block. All of them showed areas of tumor and normal columnar epithelium, type II pneumocytes or alveolar macrophages as FHIT + internal control. As a FHIT + external control we used normal kidney. New slides were reacted in an automatic immunostainer (Techmate 500, Dako) with the following antibodies: anti-FHIT polyclonal
Table 1 Clinicopathological data of NSCLC and their relation with histology

\begin{tabular}{|c|c|c|c|c|}
\hline & Total & $S C C$ & $A C$ & P-value \\
\hline No. of patients & 98 & 54 & 44 & \\
\hline Age (years) (mean) & 62.0 & 64.8 & 58.5 & 0.004 \\
\hline \multicolumn{5}{|l|}{ Sex } \\
\hline Men & 85 & 50 & 35 & 0.058 \\
\hline Women & 13 & 4 & 9 & \\
\hline Smoking (mean pack/year) & $90(49.5)$ & $54(56.3)$ & $36(41.2)$ & 0.030 \\
\hline \multicolumn{5}{|c|}{ Tumor size $(\mathrm{cm})$} \\
\hline$<3$ & 31 & 14 & 17 & NS \\
\hline$>3$ & 67 & 40 & 27 & \\
\hline \multicolumn{5}{|l|}{ Nodal status } \\
\hline No & 72 & 40 & 32 & NS \\
\hline N1-N2 & 26 & 14 & 12 & \\
\hline \multicolumn{5}{|l|}{ Stage } \\
\hline IA & 27 & 14 & 13 & NS \\
\hline IB & 44 & 25 & 19 & \\
\hline IIA & 4 & 0 & 4 & \\
\hline IIB & 15 & 8 & 7 & \\
\hline IIIA & 8 & 7 & 1 & \\
\hline Recurrence & 31 & 11 & 20 & 0.008 \\
\hline
\end{tabular}

SCC: squamous cell carcinoma; AC: adenocarcinoma; NS: nonsignificant.

antibody (PAD: ZR44, Zymed Laboratories, San Francisco, USA; 1:1200, overnight); ki-67 (7B11, Zymed Laboratories, San Francisco, USA; 1:160, overnight); p53 (DO7, Novocastra, Newcastle, UK; 1:800, overnight); c-myc (9E11, Novocastra, Newcastle, UK; 1:200, overnight); bcl-2 (clon 124, DAKO A/S, Glostrup, Denmark; 1:100, overnight); anti-bax polyclonal antibody (Biogenex, San Ramon-CA, USA; 1:3 (prediluted), overnight); p21 (4D10, Novocastra, Newcastle, UK; 1:100, overnight); and cyclinD1 (DCS-6, Novocastra, Newcastle, UK; 1:50, overnight) antibodies. All of them were developed using Envision $\oplus$ (Dako) system and DAB plus (Dako) chromogen. Antigen retrieval was performed with a microwave $(700 \mathrm{~W}, 20 \mathrm{~min})$ and citrate buffer $(10 \mathrm{mM}, \mathrm{pH}=6)$.

Immunohistochemical evaluation was performed without the knowledge of the clinical data and outcome of each case. A tumor was considered FHIT + if there was cytoplasmic reactivity in the neoplastic cells, and FHIT- if there was no cytoplasmic reaction within the neoplasm, with preserved activity in the admixed non-neoplastic cells. Immunoreactivity for p53, p21 and cyclin-D1 (nuclear staining) was scored as positive or negative with a cut point of staining $>5 \%$ of the cells. Proliferation index with ki-67 was considered a high proliferation when nuclear staining was present in more than $15 \%$ of the cells. Any cytoplasmic immunoreactivity with bcl-2, bax and c-myc antibodies was considered as positive. A bcl-2/bax ratio was calculated using the percentage of positive cells 
in 1000 tumoral cells observed in 10 different high power field (h.p.f) for each antibody.

Proliferation index was determined with ki-67 immunoexpression and flow cytometric analysis.

\section{Assays for LOH}

DNA was isolated from frozen tumor and corresponding frozen normal tissues (or peripheral blood in 21 cases) by proteinase $\mathrm{K}$ and phenol-chloroform extraction using standard protocols. Analysis of allelic losses was performed by a polymerase chain reaction (PCR)-based approach of microsatellite polymorphism analysis using microsatellite markers within (D3S1300, D3S1234) and flanking (D3S1210, D3S1312, D3S1313) the gene locus 3p14.2. The microsatellite sequences were obtained from Genome Database (www.gdb.org). D3S1300 is located within intron 5 close to exon 5, and D3S1234 within intron 8 of the FHIT gene. D3S1210 and D3S1312 are centromeric and D3S1313 is telomeric to the FHIT gene. PCR was performed using $4 \mu \mathrm{l}$ DNA solution in a final volume of $25 \mu \mathrm{l}$ containing $2.5 \mu \mathrm{l}$ of each dNTP ( $2 \mathrm{mM}), 2 \mu \mathrm{l}$ magnesium chloride $(25 \mathrm{mM})$, $2.5 \mu \mathrm{l}$ standard $10 \times$ PCR buffer, $0.2 \mu \mathrm{l}$ Taq polymerase $(5 \mathrm{U} / \mu \mathrm{l})$ and $1.5 \mu \mathrm{l}$ oligonucleotide primers $(10 \mathrm{mM})$ and $10.8 \mu \mathrm{l} \mathrm{H}_{2} \mathrm{O}$.

PCR was carried out in a GeneAmp PCR System thermocycler (Perkin-Elmer) under the following conditions: $95^{\circ} \mathrm{C}$ for $2 \mathrm{~min}$ for one cycle; 95,57 and $72^{\circ} \mathrm{C}$ for $30 \mathrm{~s}$ each one, for a total of 30 cycles; and a final extension for $7 \mathrm{~min}$ at $72^{\circ} \mathrm{C}$. All PCR products were detected by electrophoresis through $8 \%$ polyacrylamide gel followed by ethidium bromide staining and UV transillumination. This detection was carried out to ensure that the absence of FHIT PCR product was due to deletion and not to failed PCR. Aliquots of PCR products were heat denatured and separated by electrophoresis on a denaturing $6 \%$ polyacrylamide gel containing urea and detected by a fluorescent sound marker for $3^{\prime}$ oligonucleotide against (CA)n (Kits Gene images $3^{\prime}$ oligolabeling module and Gene Images CDP-Star detection module, Amersham Pharmacia Biotech). Nitrocellulose transferred membrane was exposed to an Rx plaque. Allelic losses for informative cases was scored by visual inspection if the signal intensity of one or more bands was reduced by $50 \%$ or more in the tumor DNA when compared with the nontumor DNA sample. Ambiguous results were repeated. In doubtful cases, an image analysis (OLYMPUS Microimage V.2.0) was performed to obtain a valid index of band reduction as described. ${ }^{18}$

\section{Flow Cytometry}

For cytometric study one to four $1.5 \times 1.5 \times 1.5 \mathrm{~mm}^{3}$ cubes were taken from fresh samples of tumoral tissue and were immediately frozen in liquid nitrogen and stored at $-80^{\circ} \mathrm{C}$ until analysis. At the time of analysis, nuclear suspensions were obtained according to the method described by Vindelöv et $a l^{35}$ Briefly, samples were placed in tissue culture medium (RPMI-I640) supplemented with 10\% fetal calf serum (FCs) and processed into single-cell suspensions with scissors. After centrifugation for $5 \mathrm{~min}$ at $2000 \mathrm{rpm}$, the pellet was resuspended in $2.5 \mathrm{ml}$ of citrate buffer. After another centrifugation, the following were added successively: $1800 \mu \mathrm{l}$ of solution containing trypsin, $1500 \mu \mathrm{l}$ of solution containing trypsin inhibitor and ribonuclease A, and $1500 \mu \mathrm{l}$ of solution containing propidium iodide. Before the analysis, the cell sample was filtered through a 50- $\mu \mathrm{mol} / \mathrm{l}$ nylon mesh. A minimum of $2 \times 10^{4}$ tumoral cells per sample were analyzed on an Arhens-FCS II flow cytometer as reported previously. ${ }^{36}$ The cells were chosen randomly from each tissue sample. The flow cytometric parameters evaluated included DNA ploidy and the percentage of cells in each cell cycle phase by use of the software Arhens-Acas 5.0 that was included in the system.

\section{TUNEL Assay}

To determine the apoptotic index, in situ detection of DNA strand breaks by use of the terminal doxynucleotidyl transferase-mediated dUTP nickend labeling (TUNEL) technique was performed as described previously ${ }^{37}$ with the commercially available ApopTag In Situ Apoptosis Detection Kit (ONCOR, Gaithersburg, MD, USA). Sections ( $4 \mu \mathrm{m}$ thickness) from normal and tumoral samples from selected formalin-fixed, paraffin-embedded tissue blocks were placed on coated slides and studied using TUNEL method. Briefly, tissue sections were dewaxed and rehydrated routinely. After rehydration, the slides were incubated with proteinase $\mathrm{K}$ $(20 \mu \mathrm{g} / \mathrm{ml})$ at room temperature for $15 \mathrm{~min}$. Endogenous peroxidase was inactivated by $3 \%$ hydrogen peroxide. Tissue sections were stained with an ApopTag system (ONCOR, Gaithersburg, MD, USA), which identifies cells with internucleosomal fragmentation of DNA. The reaction was terminated after $60 \mathrm{~min}$ by transfer of the slides to a coplin jar containing prewarmed working strength stop-wash buffer and incubated for $30 \mathrm{~min}$ at $37^{\circ} \mathrm{C}$. The sections were then covered with $55 \mu \mathrm{l}$ of antidigoxigenin peroxidase and incubated for $30 \mathrm{~min}$ at room temperature, and stained with diaminobenzidine to detect the labeled nuclei. For negative controls, deionized water was used instead of TdT. Positive controls consisted of inflamed human tonsil. Cells were considered positive when intense brown reactivity was detected in the nuclei. Apoptotic index was expressed as the percentage of nuclear positive stain in 1000 tumoral cells (100 cells in 10 different fields). 


\section{Statistical Analysis}

We correlated all the results with tumor histology and clinical outcome. The associations between categorical variables was tested using the test $\chi^{2}$ with a two-sided Fisher's exact test for the comparison of small groups. Relapse-free survival curves were constructed using the method of Kaplan-Meier and tested by the log-rank test. $P<0.05$ was considered to be statistically significant. Analysis was carried out using the SPSS/PC v9.0 for Windows statistical package.

\section{Results}

In normal bronchial epithelium, staining for the FHIT protein was positive in the cytoplasm. Loss of FHIT expression in tumor cells was observed in 52
$(96.3 \%)$ SCC and in $20(45.5 \%)$ AC with a statistically significant relationship $(P<0.0001)$ (Figure 1a and b). In smoker patients, 71 (78.9\%) tumors showed loss of FHIT expression, but only one $(12.5 \%)$ tumor in non-smokers were FHIT-. Statistically there was a significant inverse relation between FHIT expression and the smoking habit $(P=0.0003)$, but not with the amount of cigarettes (pack/year). Analyzing each histological type, in this series all patients with SCC were smokers and only two of them showed adequate expression of FHIT protein. The majority of smoker patients with AC $(52.8 \%)$ had tumors negative for FHIT expression. In patients with AC, there was no association between smoking and FHIT alteration $(P=0.054)$.

We found $\mathrm{LOH}$ at one or more microsatellites in $65(67.8 \%)$ of 96 informative cases: $39(72.3 \%$ of 53$)$ were SCC and $27(61.4 \%$ of 43$)$ were AC, with no
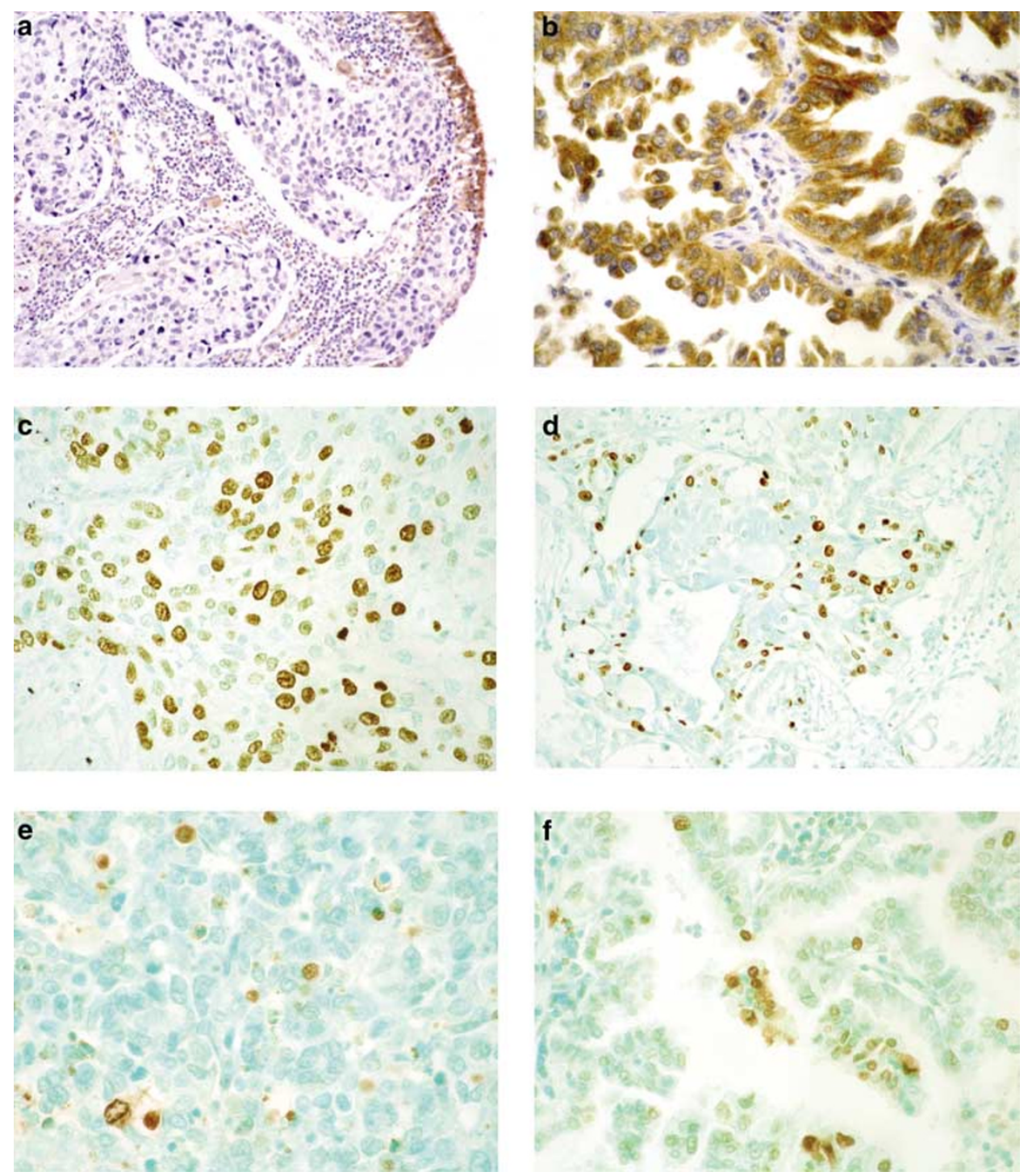

Figure 1 Photomicrographs of SCCs (left) and ACs (right) of the lung. (a and b) Examples of FHIT immunoexpression: FHIT protein is expressed in normal bronchial epithelium and in this example of lung AC, while is lost in this SCC. (c and d) Examples of ki-67 immunoexpression showing different proliferation index in SCC and in AC. (e and f) Analysis of TUNEL technique showed apoptotic cells and bodies in both types of lung carcinomas. 
statistically significant relationship $(P=0.257)$. There were 53 tumors $(55.2 \%$ of 96$)$ with $\mathrm{LOH}$ at least at one loci and loss of FHIT expression and 12 $(12.5 \%)$ with no alterations in LOH or FHIT expression $(P=0.036)$.

No correlation could be demonstrated between FHIT alteration and the patient's age at the diagnosis, histological grading, stage or pTNM.

Table 2 shows the results of the relation between p53, ki-67, c-myc, bcl-2, bax, p21 ${ }^{\text {waf1 }}$ and cyclin-D1 immunoexpression and loss of FHIT expression. The overexpression of p53 and bcl-2 was significantly associated with the loss of FHIT expression and LOH. The analysis of ki-67 expression showed 32 tumors $(32.6 \%)$ with low proliferation index and 66 tumors $(67.3 \%)$ with a high proliferation index (Figure 1c and d). Most of the cases with high ki67 expression (54/72: 75\%) had lost FHIT expression, while $14(53.9 \%)$ tumors with FHIT expression presented low ki-67 index $(P=0.007)$. The LOH and the negativity of FHIT expression were associated with a high percentage of tumoral cells in $S, G_{2}$ or $M$ phases $(P<0.001)$ (Figure 2 and Table 2$)$.

Analysis of TUNEL showed a higher percentage of apoptotic cells in FHIT + tumors (mean of 22.3\%) than in FHIT - tumors (mean of $1.3 \%)(P=0.018)$ (Figure 1e and f).

A Kaplan-Meier curve (Figure 3a and b) demonstrated that the survival rate of patients with $\mathrm{LOH}$ or negative FHIT expression was lower than that of the patients with FHIT expression or no LOH. The estimated 5-year rate of survival was $64.7 \%$ in patients with FHIT - tumors and $85.5 \%$ in FHIT + $(P=0.039)$, and $66.6 \%$ in patients with $\mathrm{LOH}$ in their tumors and $76.2 \%$ in no $\mathrm{LOH}(P=0.056)$. Statistical analysis showed that only FHIT - cases correlated significantly with a worse prognosis. These results were independent of other immunohistochemical and clinical analyzed factors.

A high percentage of tumors showed an altered expression of several proteins. The estimated rate of survival was inversely related to the number of altered proteins. Interestingly, patients with AC with loss of FHIT expression associated to c-myc and cyclin-D1 overexpression had a significant lower rate of survival $(P=0.013)$ than those tumors with no alterations of these factors (Figure 4).

\section{Discussion}

FHIT is a candidate tumor suppressor gene at chromosome $3 p 14.2$ that was identified by positional cloning. ${ }^{3}$ FHIT encompasses FRA3B, the most common fragile site in the human genome. ${ }^{3}$ Deletions and LOH within the FHIT locus and aberrant transcripts have been observed in cell lines derived from cancers and in multiple tumors including lung cancer. ${ }^{3-6,8,9,11,12,14,15}$ Such observations led to the proposal that FHIT acts as a tumor suppressor gene. The reported frequency of $\mathrm{LOH}$ at FHIT gene in
Table 2 Relation of FHIT expression in NSCLC with histology, stage, histological grading, immunohistochemical markers, proliferation index (ki-67 and flow cytometric analysis) and apoptotic index (TUNEL)

\begin{tabular}{|c|c|c|c|c|}
\hline & $\begin{array}{l}\text { Total, } \\
\mathrm{n}=98\end{array}$ & $\begin{array}{c}F H I T-(\%) \\
\mathrm{n}=72\end{array}$ & $\begin{array}{c}F H I T+(\%) \\
\mathrm{n}=26\end{array}$ & $\mathrm{P}$-value \\
\hline \multicolumn{5}{|l|}{ Histology } \\
\hline SCC & 54 & $52(96.3)$ & $2(3.7)$ & \multirow[t]{2}{*}{$<0.0001$} \\
\hline $\mathrm{AC}$ & 44 & $20(45.5)$ & $24(54.5)$ & \\
\hline \multicolumn{5}{|l|}{ Stage } \\
\hline I & 71 & $50(70.4)$ & $21(29.6)$ & \multirow[t]{2}{*}{ NS } \\
\hline II-IIIA & 27 & $22(81.5)$ & $5(18.5)$ & \\
\hline \multicolumn{5}{|l|}{ Histologic grade } \\
\hline G1-G2 & 52 & $36(69.2)$ & $16(30.8)$ & \multirow{2}{*}{ NS } \\
\hline G3 & 46 & $36(78.3)$ & $10(21.7)$ & \\
\hline \multicolumn{5}{|l|}{ p53 } \\
\hline+ & 56 & 47 (83.9) & $9(16.1)$ & \multirow[t]{2}{*}{0.007} \\
\hline- & 42 & $25(59.5)$ & $17(40.5)$ & \\
\hline \multicolumn{5}{|l|}{ Bcl-2 } \\
\hline+ & 22 & $21(95.5)$ & $1(4.5)$ & \multirow[t]{2}{*}{0.008} \\
\hline- & 76 & $51(67.1)$ & $25(32.9)$ & \\
\hline \multicolumn{5}{|l|}{ Cyclin-D1 } \\
\hline+ & 59 & 38 (64.4) & $21(35.6)$ & \multirow[t]{2}{*}{0.012} \\
\hline- & 39 & $34(87.2)$ & $5(12.8)$ & \\
\hline \multicolumn{5}{|l|}{ p21 ${ }^{\text {waf1 }}$} \\
\hline+ & 59 & 41 (69.5) & $18(30.5)$ & \multirow[t]{2}{*}{ NS } \\
\hline- & 39 & $31(79.5)$ & $8(20.5)$ & \\
\hline \multicolumn{5}{|l|}{ c-myc } \\
\hline+ & 59 & $37(62.7)$ & $22(37.3)$ & \multirow[t]{2}{*}{0.003} \\
\hline- & 39 & 35 (89.7) & $4(10.3)$ & \\
\hline \multicolumn{5}{|l|}{ Bax } \\
\hline+ & 39 & $28(71.8)$ & $11(28.2)$ & \multirow[t]{2}{*}{ NS } \\
\hline- & 59 & $44(74.6)$ & $15(25.4)$ & \\
\hline \multicolumn{5}{|l|}{ ki-67 } \\
\hline High & 66 & $54(81.8)$ & $12(18.2)$ & \multirow[t]{2}{*}{0.007} \\
\hline Low & 32 & $18(56.2)$ & $14(43.8)$ & \\
\hline \multicolumn{5}{|l|}{ Flow cytometry ${ }^{\mathrm{a}}$} \\
\hline S phase & & 4.9 & 11.8 & 0.001 \\
\hline $\mathrm{G}_{2} / \mathrm{M}$ phase & & 10.0 & 20.9 & 0.004 \\
\hline TUNEL & mean & $2.7(1.3)$ & $33.4(22.3)$ & 0.018 \\
\hline Apoptotic cells & range & $0-32.6$ & $1.2-62.5$ & \\
\hline
\end{tabular}

${ }^{\mathrm{a}}$ Median of \% of cells in each phase.

NS: nonsignificant.

NSCLC is between 20 and $70 \%$ of cases. ${ }^{5,11,17-24}$ Our results are similar to the highest frequency, with $\mathrm{LOH}$ in one or more microsatellites in $67.8 \%$ of 96 informative tumors. The differences between all series probably could be explained by the different markers used and the method of detection and evaluation of LOH. Since when different groups use the same methods, the frequencies are similar around $60 \% .^{11,12,18,22}$

Loss of immunoexpression of FHIT, the protein encoded by this gene, has been described in several 


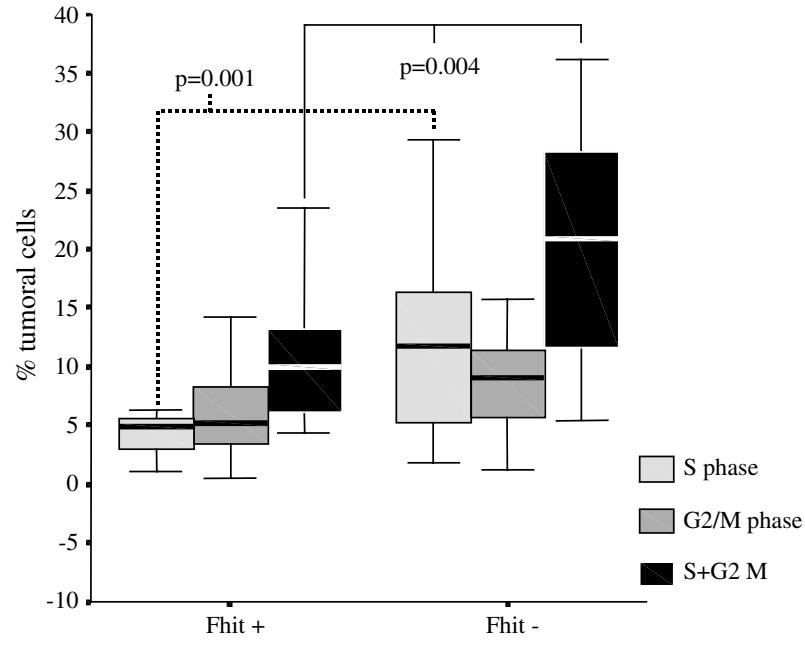

Figure 2 Schematic representation (plot bar) of the percentage of tumor cells in each flow cytometric phases related to FHIT expression.

studies in primary lung carcinomas and in cell lines from lung cancer. ${ }^{13,20,23,33,38-40}$ We detected loss of FHIT expression in a high percentage $(73.5 \%)$ of 98 lung carcinomas studied. We found $96.3 \%$ (52 of 54) SCCs with loss of FHIT expression, while only 20 of $44(45.4 \%)$ adenocarcinomas were FHIT-. This frequency is similar to the rates reported by some European and Japanese series of NSCLC ${ }^{20,40}$ and cell lines ${ }^{39}$ and it is higher than the frequency reported by others. ${ }^{13,23,33,38}$ These discrepancies may be due to differences in immunohistochemical techniques, stain interpretation or different distributions of histological types. Some authors observed an intermediate level of FHIT staining, ${ }^{33}$ but we and others $^{38,40}$ did not see it in our tumors. Our results showed that negativity of FHIT expression is more frequent in SCC than in AC $(P>0.0001)$ as has been found by others..$^{33,38,40}$ These data indicate that FHIT alterations are more commonly related to histological types of lung cancer most closely associated to smoking. A high frequency of $\mathrm{LOH}$, negative protein expression and aberrant transcripts in FHIT has been described in smokers with lung cancer and other smoking-related carcinomas of head and neck, urinary bladder and aerodigestive tract. $3,8,12,19,20,33,40-42$ These data support that cigarette smoking could induce molecular alterations of FHIT. FHIT spans the FRA3B fragile region, frequently involved in genetic arrangements described in several human tumors. ${ }^{43-45}$ FRA3B is an important target of tobacco smoke damage at a molecular level and it could explain the relationship observed between $\mathrm{LOH}$ at 3p14.2 and smoking exposure. However, the significant higher frequency of FHIT- tumors in smokers provide a direct effect of tobacco on FHIT gene and protein. Sozzi et al $1^{12,40}$ have demonstrated this effect in several studies, which has been corroborated by others. ${ }^{19,20,33}$ In our work, we observed an important prevalence of smokers between patients whose tumors showed an absence of

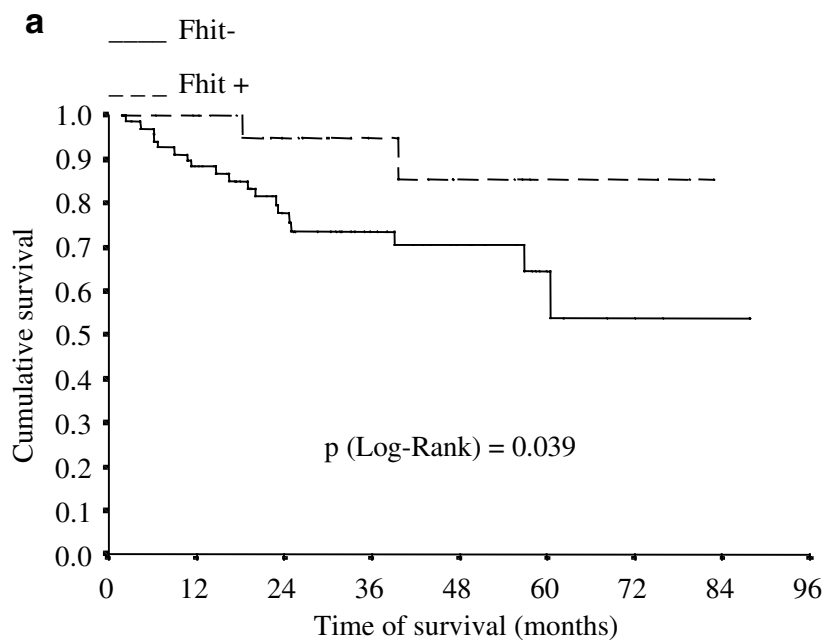

b

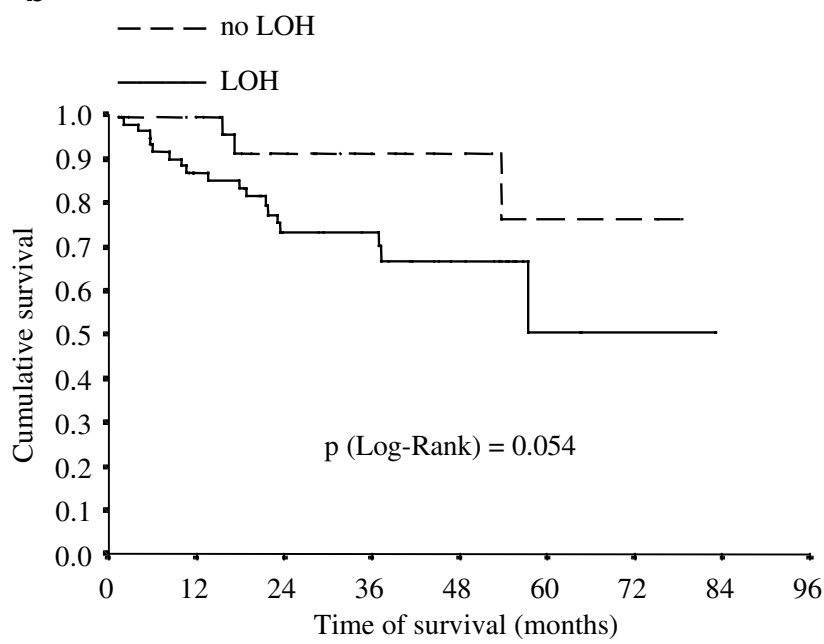

Figure 3 Kaplan-Meier cumulative survival curves according to FHIT protein expression (a) and to LOH at FHIT locus gene (b).

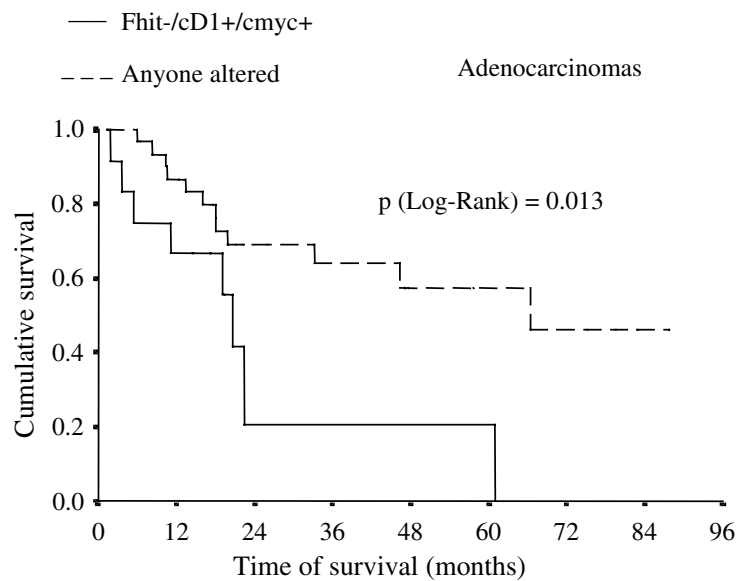

Figure 4 Kaplan-Meier cumulative survival curves showed a worse prognosis in patients with ACs with synchronic alterations in FHIT, cyclin-D1 and c-myc.

FHIT expression $(78.9 \%$ smokers vs $12.5 \%$ nonsmokers). These results heavily suggests that alterations in FHIT may be secondary to exposure of tobacco. 
Siprashvili et $a 1^{25}$ demonstrated that transfection of a plasmid with FHIT activity suppressed tumorigenicity of some FHIT - malignant cell lines when injected into nude mice. In these experiments, tumor suppression is not dependent on FHIT hydrolytic function, suggesting that an FHITnucleotide complex may be the active form. Ji et $a l,{ }^{26}$ using an adenoviral vector to transfer a highlevel expression of FHIT in human lung cancer cell lines FHIT-, observed that the tumorigenicity of such cells in nude mice was essentially eliminated in transduced cells comparing with nontransduced ones. Moreover, cell growth of adenoviral-FHITtransduced lung cancer cells was markedly inhibited in vitro, where cells arrested in S phase. ${ }^{26}$ In addition, these investigators demonstrated a high increase in the number of apoptotic transduced cells. ${ }^{26}$ Sard et $a l^{27}$ also observed similar results in malignant lung cells transfected with a plasmid with effective FHIT expression, but with cells predominantly arrested in $G_{0} / G_{1}$ phase. The increase in apoptosis was independent of bcl-2, bcl-X and bax in the FHIT-transfected cells, ${ }^{27}$ and these authors have suggested that apoptosis in FHIT - cells could be induced trough the caspases pathway. ${ }^{27,46}$ The inhibition of cell growth seems related to a significant increase of the cell cycle inhibitory protein p21, with independence of p53 levels. ${ }^{27}$ Similar observations described in a human myeloid leukemia cell $\operatorname{line}^{47}$ support a potential relationship between FHIT and apoptosis. However, the relationship between FHIT and tumoral growth, inhibition of cell cycle and apoptosis has not been found in other investigations. ${ }^{16,39,48}$ The structural features of FHIT protein, its role in nucleotide metabolism and the amount of Ap3A and Ap4A, substrates of FHITmediated hydrolysis, in cellular stress, also suggest that FHIT can play some role as a cell cycle inhibitor factor and a stimulator of apoptosis. ${ }^{4}$ There are a few studies in lung cancer biopsies in which proliferation index of tumoral cells were compared to FHIT expression, with a significant correlation between both factors. ${ }^{18,20}$ We have found a significant correlation between negative FHIT expression and the high proliferation index detected with both ki-67 immunoexpression and flow cytometric analysis. These data are similar to those found in vitro by other investigators. ${ }^{27}$ Although we observed a relationship between p53 overexpression and loss of FHIT $(P=0.007)$, the association of FHIT with proliferation index was statistically independent of the presence of p53 or p21 $1^{\text {waf-1 }}$ overexpression.

In our study, with the TUNEL technique, FHITtumors showed a lower index of apoptosis $(1.3 \%)$ than FHIT + carcinomas $(22.3 \%)(P=0.018)$. We could not find a correlation between apoptotic data and the immunoexpression of bcl-2 and bax antibodies. Sard et $a l^{27}$ and Ji et $a l^{26}$ observed similar results.

The relationship between alteration of FHIT expression, an increased proliferation index and low apoptosis is in agreement with a high aggressiveness of these tumors. We have found a significant worse prognosis in patients whose tumors showed an altered FHIT expression. The 5-year survival rate of patient with tumors with adequate FHIT expression was significantly higher $(85.5 \%)$ than in tumors FHIT- $(64.7 \%)(P=0.039)$. This investigations in lung cancer ${ }^{17,33}$ as in other tumors $^{28,30-32}$ suggest that FHIT alteration is associated with a high proliferation index that results in an aggressive behavior. Tomizawa et $a l^{33}$ reported a significant poor survival in FHIT - tumors in a series of stage I NSCLC. However, the correlation between loss of FHIT and poor prognosis in NSCLC has not been observed by others. . $^{59,20,23,38,40}$ In this series, we observed that lung AC with synchronous alteration of FHIT (loss of expression), c-myc (overexpression) and cyclin-D1 (overexpression) have worse prognosis.

In conclusion, our results support that FHIT plays an important role in the carcinogenesis of NSCLC. It appears particularly important in SCC and associated with smoking. Loss of FHIT protein expression is correlated with a high proliferation index and with low apoptotic index, indicating that tumoral cells showed more aggressive behavior. Loss of FHIT expression results in an indicator of worse prognosis and may be an independent marker for the clinical outcome in patients with these tumors.

\section{Acknowledgements}

We thank Loli Martínez and Marian Martínez for expert technical assistance in the immunohistochemical procedures, and Merche Aguirre in the molecular biology assays. This work has been presented in part in 92nd United States and Canadian Academy of Pathology (USCAP) Annual Meeting (Washington, DC, USA, March 8-14, 2003).

\section{References}

1 Black RJ, Bray F, Ferlay J, et al. Cancer Incidence and Mortality in the European Union: cancer registry data and estimates of national incidence for 1990. Eur J Cancer 1997;33:1075-1107.

2 Greenlee RT, Hill-Harmon MB, Murray T, et al. Cancer statistics, 2001. CA Cancer J Clin 2001;51:15-36.

3 Ohta M, Inoue H, Cotticelli MG, et al. The FHIT gene, spanning the chromosome 3p14.2 fragile site and renal carcinoma-associated $\mathrm{t}(3 ; 8)$ breakpoint, is abnormal in digestive tract cancers. Cell 1996;84:587-597.

4 Brenner C, Bieganowski P, Pace HC, et al. The histidine triad superfamily of nucleotide-binding proteins. J Cell Physiol 1999;181:179-187.

5 Fong KM, Biesterveld EJ, Virmani A, et al. FHIT and FRA3B 3p14.2 allele loss are common in lung cancer and preneoplastic bronchial lesions and are associated with cancer-related FHIT cDNA splicing aberrations. Cancer Res 1997;57:2256-2267. 
6 Fullwood P, Marchini S, Rader JS, et al. Detailed genetic and physical mapping of tumor suppressor loci on chromosome $3 p$ in ovarian cancer. Cancer Res 1999;55:4662-4667.

7 Guo Z, Wu F, Asplund A, et al. Analysis of intratumoral heterogeneity of chromosome $3 p$ deletions and genetic evidence of polyclonal origin of cervical squamous carcinoma. Mod Pathol 2001;14:54-61.

8 Kastury K, Baffa R, Druck T, et al. Potential gastrointestinal tumor suppressor locus at the 3p14.2 FRA3B site identified by homozygous deletions in tumor cell lines. Cancer Res 1996;56:978-983.

9 Maitra A, Wistuba II, Washington C, et al. High resolution chromosome $3 p$ allelotyping of breast carcinomas and precursors lesions demonstrates frequent loss of heterozigosity and a discontinuous pattern of allele loss. Am J Pathol 2001;159:119-130.

10 Negrini M, Monaco C, Vorechovsky I, et al. The FHIT gene at 3 p14.2 is abnormal in breast carcinomas. Cancer Res 1996;56:3173-3179.

11 Sozzi G, Veronese ML, Negrini M, et al. The FHIT gene at 3p14.2 is abnormal in lung cancer. Cell 1996;85:17-26.

12 Sozzi G, Sard L, De Gregorio L, et al. Association between cigarette smoking and FHIT gene alterations in lung cancer. Cancer Res 1997;57:2121-2123.

13 Sozzi G, Tornielli S, Tagliabue E, et al. Absence of FHIT protein in primary lung tumors and cell lines with FHIT gene abnormalities. Cancer Res 1997;57:5207-5212.

14 Velickovic M, Delahunt B, Grebe SK. LOH at 3p14.2 in CCRC (clear cell renal carcinoma) is an early event and is highly localized to the FHIT gene locus. Cancer Res 1999;59:1323-1326.

15 Virgilio L, Schuster M, Gollin SM, et al. FHIT gene alterations in head and neck squamous cell carcinomas. Proc Natl Acad Sci USA 1996;93:9770-9775.

$16 \mathrm{Wu}$ R, Connolly DC, Dunn RL, et al. Restored expression of fragile histidine triad protein and tumorigenicity of cervical carcinoma cells. J Natl Cancer Inst 2000;92:338-344.

17 Burke L, Khan MA, Freedman AN, et al. Allelic deletion analysis of the FHIT gene predicts poor survival in non-small cell lung cancer. Cancer Res 1998;58:2533-2536.

18 Garinis GA, Gorgoulis VG, Mariatos G, et al. Assosiation of allelic loss at the FHIT locus and p53 alterations with tumour kinetics and chromosomal instability in non-small cell lung carcinomas (NSCLCs). J Pathol 2001;193:55-65.

19 Marchetti A, Pellegrini S, Bertacca G, et al. FHIT and p53 gene abnormalities in bronchioloalveolar carcinomas: correlations with clinicopathological data and Kras mutations. J Pathol 1998;184:240-246.

20 Pavelic K, Krizanac S, Cacev T, et al. Aberration of FHIT gene is associated with increased tumor proliferation and decreased apoptosis-clinical evidence in lung and head and neck carcinomas. Mol Med 2001;7:442-453.

21 Sozzi G, Musso K, Ratcliffe C, et al. Detection of microsatellite alterations in plasma DNA of non-small cell lung cancer patients: a prospect for early diagnosis. Clin Cancer Res 1999;5:2689-2692.

22 Tokuchi Y, Kobayashi Y, Hayashi S, et al. Abnormal FHIT transcripts found in both cancer and normal lung tissue. Genes Chromosomes Cancer 1999;24:105-111.

23 Tseng JE, Kemp BL, Khuri FR, et al. Loss of Fhit is frequent in stage I non-small cell lung cancer and in the lungs of chronic smokers. Cancer Res 1999;59:4798-4803.

24 Wistuba II, Behrens C, Virmani AK, et al. High resolution chromosome $3 p$ allelotyping of human lung cancer and preneoplastic/preinvasive bronchial epithelium reveals multiple, discontinuous sites of $3 \mathrm{p}$ allele loss and three regions of frequent breakpoints. Cancer Res 2000;60:1949-1960.

25 Siprashvili Z, Sozzi G, Barnes LD, et al. Replacement of Fhit in cancer cells suppresses tumorigenicity. Proc Natl Acad Sci USA 1997;94:13771-13776.

26 Ji L, Fang B, Yen N, et al. Induction of apoptosis and inhibition of tumorigenicity and tumor growth by adenovirus vector-mediated fragile histidine triad (FHIT) gene overexpression. Cancer Res 1999;59: 3333-3339.

27 Sard L, Accornero P, Tornielli S, et al. The tumorsuppressor gene FHIT is involved in the regulation of apoptosis and in cell cycle control. Proc Natl Acad Sci USA 1999;96:8489-8492.

28 Capuzzi D, Santoro E, Hauck WW, et al. FHIT expression in gastric adenocarcinoma: correlation with disease stage and survival. Cancer 2000;88:24-34.

29 Eyzaguirre EJ, Miettinen M, Norris BA, et al. Different immunohistochemical patterns of FHIT protein expression in renal neoplasms. Mod Pathol 1999;12:979-983.

30 Lee JI, Soria JC, Hassan K, et al. Loss of FHIT expression is a predictor of poor outcome in tongue cancer. Cancer Res 2001;61:837-841.

31 Ramp U, Caliskan E, Ebert T, et al. FHIT expression in clear cell renal carcinomas: versatility of protein levels and correlation with survival. J Pathol 2002;196:430-436.

32 Shimada Y, Sato F, Watanabe G, et al. Loss of fragile histidine triad gene expression is associated with progression of esophageal squamous cell carcinoma, but not with the patient's prognosis and smoking history. Cancer 2000;89:5-11.

33 Tomizawa Y, Nakajima T, Kohno T, et al. Clinicopathological significance of FHIT protein expression in stage I non-small cell lung carcinoma. Cancer Res 1998;58:5478-5483.

34 Travis WD, Colby TV, Corrin B, et al. Histological classification of lung and pleural tumours. In: World Health Organization (WHO), Travis WD (ed). Histological Typing of Lung and Pleural Tumors, Vol. 1, 3rd edn. Heidelberg, Germany: Springer Verlag, 1999, pp 21-24.

35 Vindelöv L, Christensen I, Nissen N. A detergenttrypsin method for the preparation of nuclei for flow cytometric DNA analysis. Cytometry 1983;3:323-327.

36 Panizo-Santos A, Sola JJ, Pardo-Mindán FJ, et al. Angiotensin converting enzyme inhibition prevents polyploidization of cardiomyocytes in spontaneously hypertensive rats with left ventricular hypertrophy. J Pathol 1995;177:431-437.

37 Gavrieli Y, Sherman Y, Ben-Sasson SA. Identification of programmed cell death in situ via specific binding of nuclear DNA fragmentation. J Cell Biol 1992;119: 493-501.

38 Geradts J, Fong KM, Zimmerman PV, et al. Loss of FHIT expression in non-small-cell lung cancer: correlation with molecular genetic abnormalities and clinicopathological features. Br J Cancer 2000;82: 1191-1197.

39 Otterson GA, Xiao GH, Geradts J, et al. Protein expression and functional analysis of the FHIT gene in human tumor cell. J Natl Cancer Inst 1998;90:426-432. 
40 Sozzi G, Pastorino U, Moiraghi L, et al. Loss of FHIT function in lung cancer and preinvasive bronchial lesions. Cancer Res 1998;58:5032-5037.

41 Baffa R, Veronese ML, Santoro R, et al. Loss of FHIT expression in gastric carcinoma. Cancer Res 1998;58: 4708-4714.

42 Baffa R, Gomella L, Vecchione A, et al. Loss of FHIT expression in transitional cell carcinoma of the urinary bladder. Am J Pathol 2000;156:419-424.

43 Croce CM, Sozzi G, Huebner K. Role of FHIT in human cancer. J Clin Oncol 1999;17:1618-1624.

44 Michael D, Rajewsky MF. Induction the common fragile site FRA3B does not affect FHIT expression. Oncogene 2001;20:1798-1801.
45 Sutherland GR, Richards RI. The molecular basis of fragile sites in human chromosomes. Curr Opin Genet Dev 1995;5:323-327.

46 Roz L, Gramegna M, Ishii H, et al. Restoration of fragile histidine triad (FHIT) expression induces apoptosis and suppresses tumorigenicity in lung and cervical cancer cell lines. Proc Natl Acad Sci USA 2002;99: 3615-3620.

47 Vartanian A, Prudovsky I, Suzuki H, et al. Opposite effects of cell differentiation and apoptosis on Ap3A/Ap4A ratio in human cell cultures. FEBS Lett 1997;415:160-162.

48 Huebner K, Garrison PN, Barnes LD, et al. The role of the FHIT/FRA3B locus in cancer. Annu Rev Genet 1998;32:7-31. 